\title{
The level and quality of social services in crisis intervention in Slovakia in the field of gender-based violence
}

\author{
Soňa Šrobárová - Martina Špániková \\ Catholic University in Ruzomberok / Department of Social Work
}

\begin{abstract}
The research problem that below approaching we processed on the basis of theoretical and practical knowledge in relation to social work crisis intervention. The issue of crisis intervention is currently highly topical issue that requires more attention, not only in terms of training, but also the general public, respectively society as a whole. The most effective result in terms of the macro level, so the company would be considered the one that we have crisis intervention due to the elimination of eliminating serious problem situations in society encourage positive change cultural and social situation. Crisis intervention is characterized mainly by working with a person, family, community problems within having increased to extreme stress, which can cause severe stress to posttraumatic shock, which is not associated with the possible occurrence of post-traumatic stress disorder. Meaning crisis intervention and of interventions targeted social worker in practice is that it helps the client, his family and the community cope with symptoms associated with posttraumatic stress and even prevent such serious psychological, physiological and psychosomatic problems. Based on the above, it is important to assess and analyze the provision of crisis intervention in Slovakia in general and in terms of providing selected services in crisis intervention facilities in the context of gender-based violence. Services and their provision is linked to the selected methods and techniques of social work, which are used in emergency facilities.
\end{abstract}

Keywords: crisis; crisis intervention department; secondary victim; service; social help 